\title{
Study On The External Gas-Assisted Mold Temperature Control For Thin Wall Injection Molding
}

\author{
ThanhTrung Do*, Tran Minh TheUyen*, Pham Son Minh* \\ * HCMC University of Technology and Education, Vietnam
}

\begin{abstract}
Dynamic mold surface temperature control (DMTC) has many advantages in micro-injection molding as well as thin-wall molding product. In this paper, DMTC will be applied for the thin-wall molding part with the observation of the weldline appearance and the weldline strength. The heating step of DMTC will be achieved by the hot air flow directly to the weldline area. The results show that the heating rate could be reached to $4.5^{\circ} \mathrm{C} / \mathrm{s}$, which could raising the mold surface from $30^{\circ} \mathrm{C}$ to over $120^{\circ} \mathrm{C}$ within $15 \mathrm{~s}$. The melt filling was operated with high temperature at the weldline area; therefore, the weldline appearance was eliminated. In addition, the weldline strength was also improved. The results show that the thinner part had the higher strength of the weldline.
\end{abstract}

Keywords: injection molding, thin-wall part, dynamic mold temperature control, mold heating, heating rate

\section{INTRODUCTION}

Thin-wall molding has been applied to make a variety of polymer components. Most applications are in the field of biomedical and micro fluidics [1-3]. Another widespread micro-molded article is the holograms fixed to credit cards. Other molded micro-optical components include optical gratings, optical switches, and waveguides. While there are also a variety of molded micro-fluidic devices, such as pumps and capillary analysis systems, the largest market is expected to be for labon-a-chip applications. Because of its short cycle times, injection molding is the process most frequently used for micro-molding inindustries.

Several micro-molding machines are sold on the market and mold inserts fabricated with various techniques suitable for most applications are available. This is reflected by an increasing interest of industries in micro-molding processes. In order to fabricate a micro-structured tool (mold insert), the miniaturization of chemical and mechanical devices for micro-electromechanical systems (MEMS) has received a great deal of attention [4-6]. The appearance of the LIGA-like technology led to a new challenge in the thermoplastic molding of micro-structures, i.e., replication of high aspect ratios (A.R.). As a result, mold filling and draft angle design for demolding have become key issues. Groove and pin holds of some hundred microns in depth and a few microns in width require high mold temperatures to improve the melt filling. To adapt conventional injection molding to the molding of high A.R. micro-features, operations at very high mold temperatures, close to the melt temperature, and integral heating of the mold are used, for complete mold filling. However, while high mold temperatures help eliminate many molding problems, in an injection cycle, the cooling processoccupies about two-thirds of the cycle time. As a result, a variety of dynamic mold temperature controls have been explored in recent years. Their purpose is to eliminate the frozen layer, to ideally have a hot mold during the filling stage and a cold mold for cooling.

The most inexpensive way to achieve a high mold temperature is to run cooling water at temperatures as high as $90^{\circ} \mathrm{C}$ or even $100^{\circ} \mathrm{C}$ [7]. When a mold temperature exceeding $100^{\circ} \mathrm{C}$ is required, either a high pressure water supply system (to prevent the water from steaming) or a heated oil may be used. The former may cause channel connection damage and safety issues after long-term operation, while the latter may not be energyefficient due to the low heat transfer coefficient of oil. Local mold heating using electric heating elements is sometimes used to assist high mold temperature control, especially for thin-wall cavity areas. However, this requires additional design and tool costs. Further, electrical heating is usually used as an auxiliary heating and is limited to increases in mold temperature of roughly several tens of degrees centigrade. Unfortunately, maintaining a high mold temperature during the filling process and then lowering the mold temperature to below deflection temperature during the post-filling process without great increases in cycle time and energy consumption is not easy [8-10]. In this paper, the effects of rapid mold surface temperature control within short periods using gas-assisted heating between high and low temperatures on the 
replication accuracy of micro-featured surfaces is investigated.

\section{GAS-ASSISTED MOLD TEMPERATURE CONTROL (GMTC) SYSTEM}

Gas-assisted mold temperature control (GMTC) is a new technique in the field of mold temperature control. It can heat and cool the cavity surface rapidly during the injection molding process. In general, the goals of mold temperature control are to increase the mold surface to the target temperature before the filling of melt and to cool the melt to the ejection temperature. In this research, the GMTC system consists of a GMTC controller, hot-gas generator system (including air compressor, air drier, a digital volumetric flow controller, and a high efficiency gas heater), and water mold temperature controller as shown in Fig. 1.

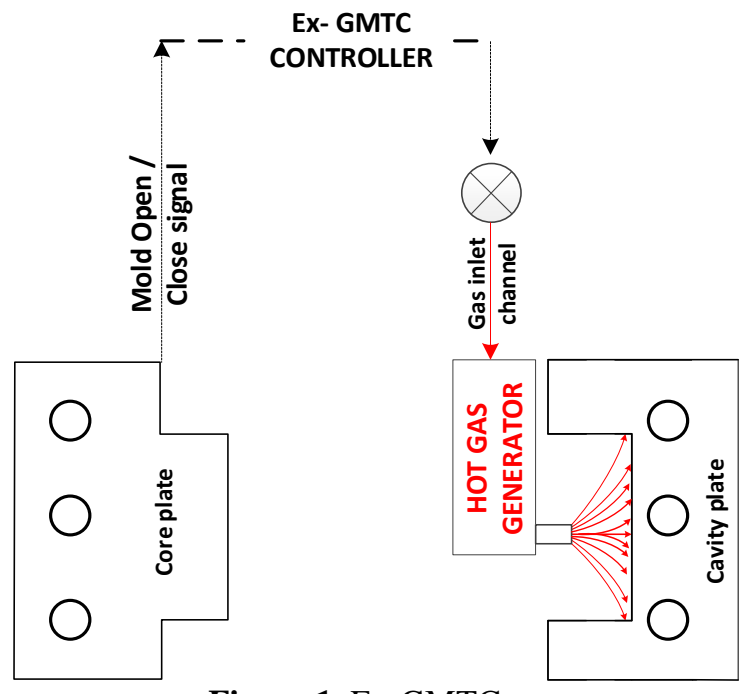

Figure 1. Ex-GMTC system

In this paper, the hot gas is used as a heating source to increase the cavity surface temperature of the injection mold. Then, after the filling process is finished, the hot melt is solidified by using the cool water. For operation, first, by closing the mold, the core moves to the heating position. Second, the hot gas is flowed into the cavity and all the cool air is pushed out; thus, only the hot gas appears and flows inside the cavity. Therefore, the heat transfer coefficient increases very fast. The energy transferred from the hot gas to the mold wallheats the cavity surface. This is the heating process of the gas-assisted mold surface heating in injection molding. Third, when the cavity surface is heated to the target temperature for assistance in the filling and packing of the melt, the mold is completely closed in preparation for the filling process.

\section{EXPERIMENTALWORK}

A 120-ton Shin Well injection molding machine, equipped with an accumulator capable of delivering a maximum flow rate of $125 \mathrm{~cm}^{3} / \mathrm{s}$ and providing a maximum injection pressure of 150 $\mathrm{MPa}$, was utilized for experiments. A tensile test specimen mold (Fig. 3), which allows the thickness of the weldline area to vary between $0.3 \mathrm{~mm}, 0.5$ $\mathrm{mm}$, and $0.7 \mathrm{~mm}$, was designed to conduct the experiments. The geometry of the tensile strength specimen is shown in Fig. 2. Double-gate inserts were employed so thatthepolypropylene (PP) test specimens can be molded with weldlines. To control the mold temperature at the weldline area, an insert block was manufactured as shown in Fig. 4. This block enhances the thermal energy from the hot air focused on the weldline area, so the heating time could be reduced. A PCbased monitoring system was established to supervise the process conditions such as hydraulic oil pressure, nozzle pressure, cavitypressures, and screw position. Polypropylen (ABS) resin was used as the molding material. Because of high-speed injection and quick filling time requirements for thin-wall molding, molding window was quite limited, particularly, when part becomes thinner. In order to investigate the influence of processing condition on part mechanical properties for parts with weldline, after several trials, the melt temperature was chosen to be $220^{\circ} \mathrm{C}$. Furthermore, the flow rate and packing pressure were $110 \mathrm{~cm}^{3} / \mathrm{s}$ and $60 \mathrm{MPa}$, respectively. These processing parameters served as the standard molding criteria, then one parameter was altered with three different levels to investigate the effects of individual parameters on part tensile strength

The study of the mechanical properties includes tensile test measurement. For each type of testing, five samples molded under the same molding conditions were used. Then, the average value of five test specimens was used for analysis and correlation. The specimen dimensions varied considerably depending on the experimental requirements and the tensile test procedures followedinthe ASTM D638 Standard.Tensile strength test was conducted on a HT-8503 machine with full loads of $500 \mathrm{kgfand}$ a displacement rate was employed at $5 \mathrm{~mm} / \mathrm{min}$. The specimen broke around the center portion in spite of the existence of weldline. The variations of tensile strength for both weldline and non-weldline parts with processing conditions were investigated carefully, as far as part residual stresses, which were evaluated using a laboratory-developed photoelasticity system where fringe patterns were analyzed using digital image techniques. 


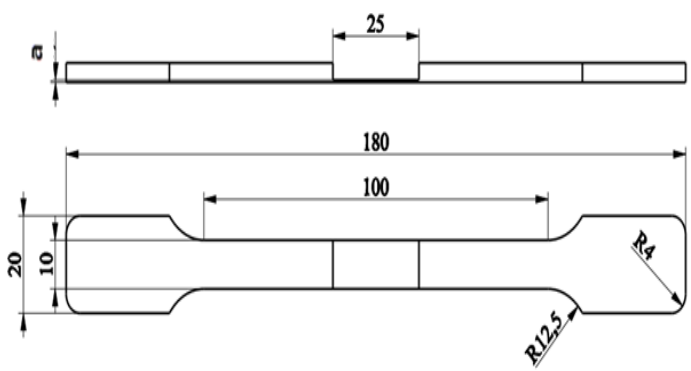

Figure 2. Mold geometry of the tensile test specimen

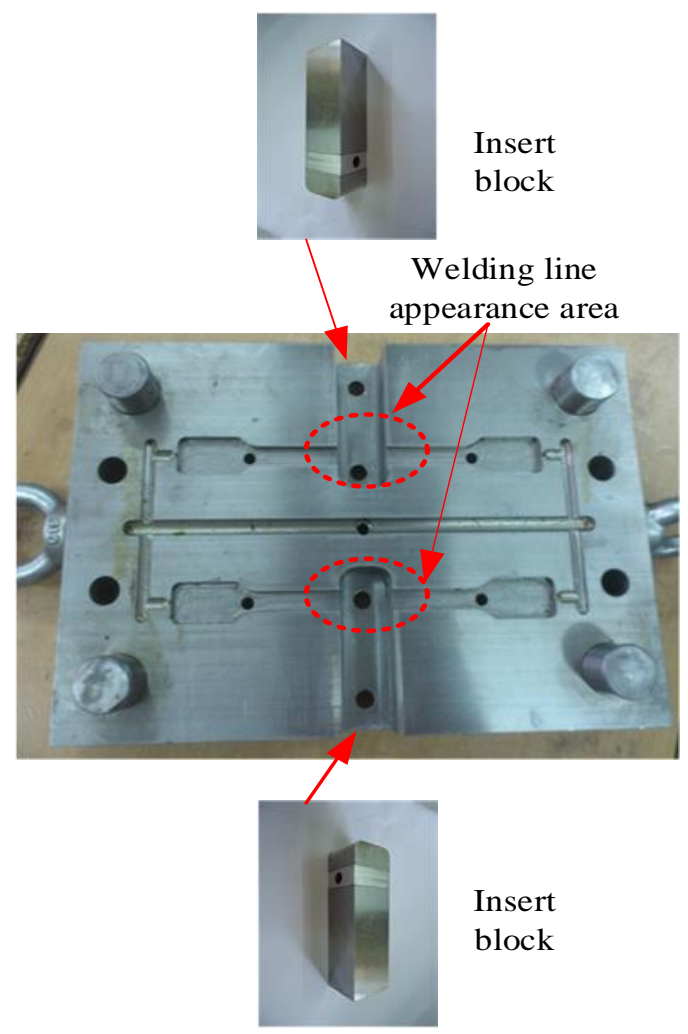

Figure 3. Mold structure
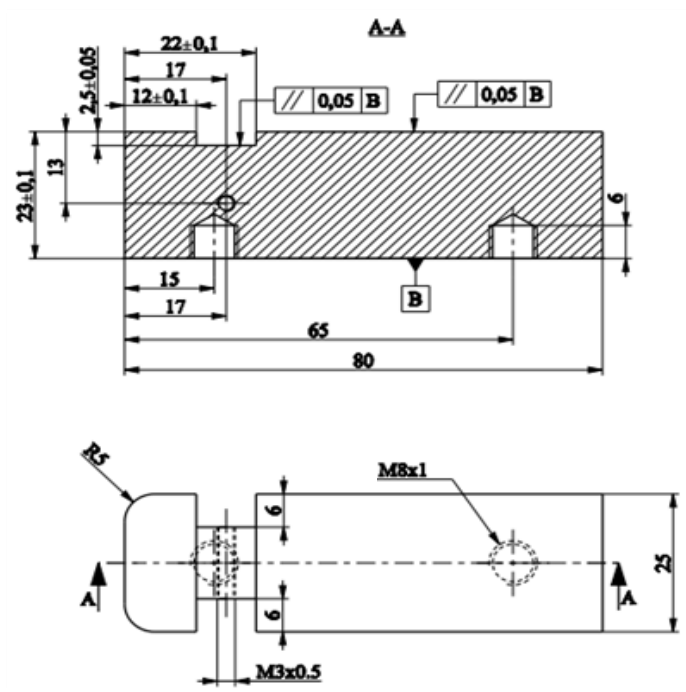

Figure 4.Dimension of the insert block

\section{RESULTS AND DISCUSSIONS}

The variation in the mold temperature (at the weldline appearance area - Fig. 3) versus time for a heating time of $60 \mathrm{~s}$ was collected and compared as in Fig. 5. For an initial mold temperature of $30^{\circ} \mathrm{C}$, it can be seen that the ExGMTC can heat the plate to above $120^{\circ} \mathrm{C}$ after $20 \mathrm{~s}$ of heating. This temperature is higher than the glass transition temperature of PP materials. Based on this result, the heating rate could be reached to $4.5^{\circ} \mathrm{C} / \mathrm{s}$, which is accepted when compared with former researches regarding temperature controls for injection molding [2, 10, 12, 13, 14, 17, and 18]. In our former papers, when the GMTC was used for a heating area of $60 \mathrm{~mm} \times 25 \mathrm{~mm}$, a gas flow rate of $500 \mathrm{~L} / \mathrm{min}$ and a gas temperature of $500^{\circ} \mathrm{C}$ was achieved; the highest heating rate was just about $2.2^{\circ} \mathrm{C} / \mathrm{s}$. It means that the Ex-GMTC has a great advantage in terms ofthe heating efficiency on the mold surface, especially with local heating as in this research.

To demonstrate the effect of variable mold surface temperature control on the real molding case, a mold surface of a double-gated tensile test specimen was used for the experiment (Fig. 3). The experiment model is shown in Fig. 2. Initially in the experiment, all mold structures were at room temperature $\left(30^{\circ} \mathrm{C}\right)$. Then, the weldline appearance area of the cavity plate was heated with temperature targets of $60^{\circ} \mathrm{C}, 90^{\circ} \mathrm{C}$, and $120^{\circ} \mathrm{C}$. Next, the mold plates were closed and the injection cycle of the PP resin began. In this paper,theEx-GMTC was applied for one cavity, and by using a temperature sensor, the temperature at the weldline area was collected. In addition, the tensile strength was studied for different heating targets and on different thicknesses of the tensile bar. In addition, the influence of the Ex-GMTC on the weldlinewas studied under three part thicknessesof $0.7 \mathrm{~mm}, 0.5 \mathrm{~mm}$, and $0.3 \mathrm{~mm}$.

To estimate the influence of injection molding on the weldline of the injection molding process, the tensile bar was collected and checked visually and by tensile testing. First, for visual testing with three part thicknesses, the appearance of the weldline is quite clear as indicated in Figs. 6, 7, and 8 . These results show that with the heating target of $120^{\circ} \mathrm{C}$, the weldline mark almost disappeared. Second, through tensile testing conducted at various targets of heating temperature, the weldline strength is indicated by 10 samples in each case; the weldline strength is shown in Table 1 and Fig. 9. According to this result, the weldline strength increased with the higher mold temperature. This indicates that the weldline problem can be solved using few seconds of air heating on mold surface without a significant increase in cycle time. In addition, weldline strength is higher in the thinner part. This result is due to the fact that the high temperature area of the 
weldlinearea allows the melt to mix easier, therefore, the effect on the weldline is stronger.

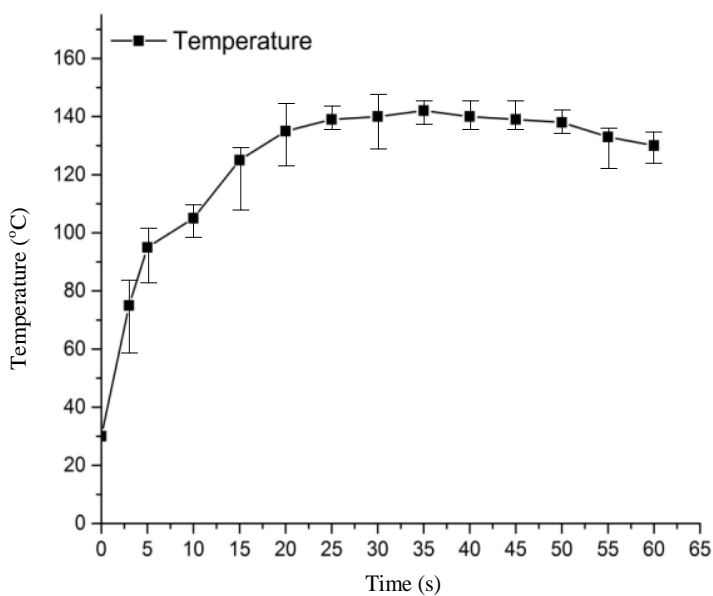

Figure 5. Temperature history at the weldline area with the Ex-GMTC

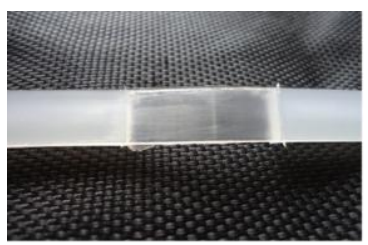

$0.7 \mathrm{~mm}$ thickness

$30{ }^{\circ} \mathrm{C}$ mold temperatre

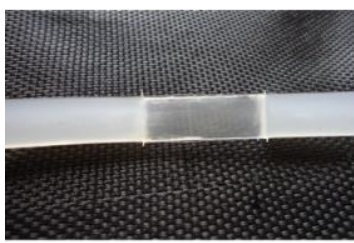

$0.7 \mathrm{~mm}$ thickness

$90{ }^{\circ} \mathrm{C}$ mold temperatre

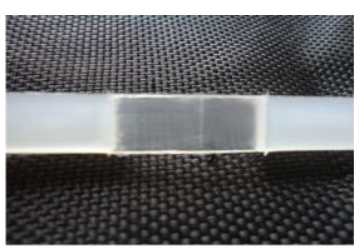

$0.7 \mathrm{~mm}$ thicknes $60{ }^{\circ} \mathrm{C}$ mold temperatre

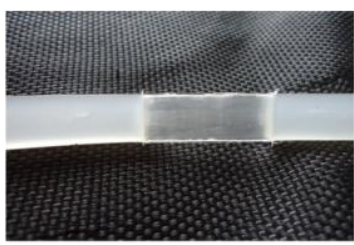

$0.7 \mathrm{~mm}$ thicknes

$120{ }^{\circ} \mathrm{C}$ mold temperatre
Figure 6. Weldline appearance with part thickness of $0.7 \mathrm{~mm}$

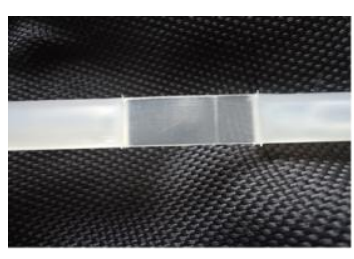

$0.5 \mathrm{~mm}$ thickness

$30{ }^{\circ} \mathrm{C}$ mold temperatre

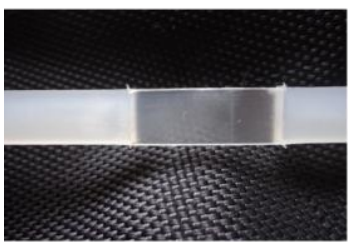

$0.5 \mathrm{~mm}$ thickness $90{ }^{\circ} \mathrm{C}$ mold temperatre

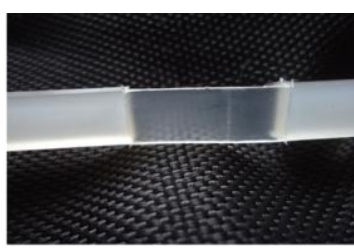

$0.5 \mathrm{~mm}$ thickness $60{ }^{\circ} \mathrm{C}$ mold temperatre

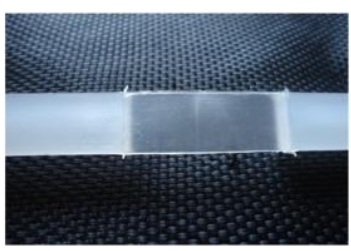

$0.5 \mathrm{~mm}$ thickness $120{ }^{\circ} \mathrm{C}$ mold temperatre
Figure 7. Weldline appearance with part thickness of $0.5 \mathrm{~mm}$

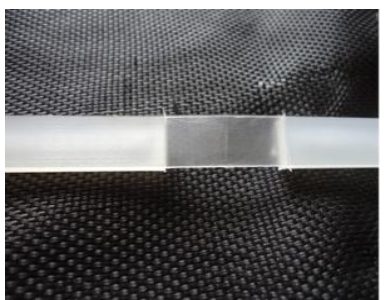

$0.3 \mathrm{~mm}$ thickness

$30{ }^{\circ} \mathrm{C}$ mold temperatre

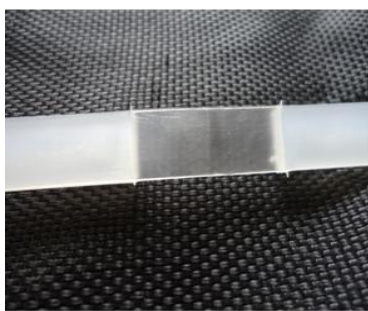

$0.3 \mathrm{~mm}$ thicknes

$90{ }^{\circ} \mathrm{C}$ mold temperatre

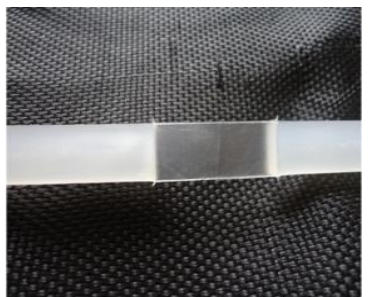

$0.3 \mathrm{~mm}$ thickness

$60{ }^{\circ} \mathrm{C}$ mold temperatre

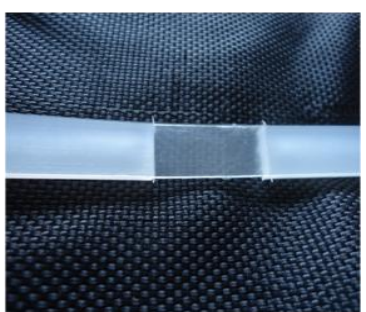

$0.3 \mathrm{~mm}$ thickness

$120{ }^{\circ} \mathrm{C}$ mold temperatre
Figure 8. WeldlineappeaRance with part thickness of $0.3 \mathrm{~mm}$

Table 1.Weldline strength under different mold temperatures

\begin{tabular}{|c|c|c|c|c|}
\hline & \multicolumn{4}{|c|}{ Heating target } \\
\hline $\begin{array}{c}\text { Part } \\
\text { thickness }\end{array}$ & $30^{\circ} \mathrm{C}$ & $60^{\circ} \mathrm{C}$ & $90^{\circ} \mathrm{C}$ & $120^{\circ} \mathrm{C}$ \\
\hline $0.3 \mathrm{~mm}$ & 44.87 & 47.82 & 49.34 & 49.78 \\
\hline $0.5 \mathrm{~mm}$ & 24.24 & 34.09 & 35.72 & 36.74 \\
\hline $0.7 \mathrm{~mm}$ & 29.98 & 31.6 & 33.57 & 34.28 \\
\hline
\end{tabular}

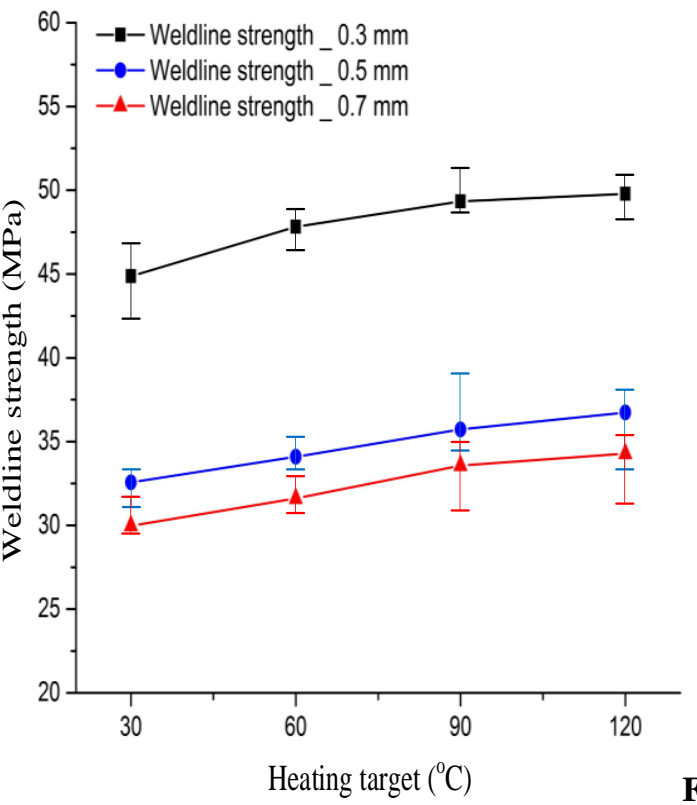

ure 9.Weldline strength under different heating targets and part thicknesses 


\section{CONCLUSIONS}

In this study, three thicknesses of tensile strength specimen were tested with different mold temperatures. The mold temperature was controlled by the Ex-GMTC method. The results prove that the Ex-GMTC method provides an efficient way for mold surface heating; thus, it can be applied to realtime injection molding cases. The mold surface temperature was raised above the glass transition temperature instantly within a few seconds (15 s) and the mold was closed for melt injection and cooled down to a regular mold temperature before the next cycle starts. The effects of various temperatures on the molded part's qualities, such as weldline appearance and weldline strength,were examined. It was found that the appearance of a weldline on the surface can be eliminated, and the associated weldline strengths were enhanced for molding multi-gated tensile test parts. The rapid heating of the mold surface using the Ex-GMTC method was successfully illustrated.

\section{REFERENCES}

[1]. N. D. F. Daudt, M. Bram, A. P. C. Barbosa, A. M. Laptev, C. Alves, Manufacturing of highly porous titanium by metal injection molding in combination with plasma treatment, Journal of Materials Processing Technology, 239, 2017, 202-209.

[2]. D. Masato, M. Sorgato, G. Lucchetta, Analysis of the influence of part thickness on the replication of micro-structured surfaces by injection molding, Materials \& Design, 95(5), 2016, 219-224.

[3]. M. Zhou, B. Jiang, C. Weng, Molecular dynamics study on polymer filling into nanocavity by injection molding, Computational Materials Science, 120, 2016, 36-42.

[4]. C. S. Chena, S. C. Chenb, W. H. Liaod, R. D. Chien, S. H. Lin, Micro injection molding of a micro-fluidic platform, International Communications in Heat and Mass Transfer, 37(9), 2010, 1290-1294.

[5]. G. Lucchettaa, M. Sorgatoa, S. Carmignatob, E. Savioa, Investigating the technological limits of micro-injection molding in replicating high aspect ratio micro-structured surfaces, CIRP Annals - Manufacturing Technology, 63(1), 2014, 521-524.

[6]. M. Wanga, J. Lia, K. Ngob, H. Xie, Silicon molding techniques for integrated power MEMS inductors, Sensors and Actuators A: Physical, 166(1), 2011, 157-163.

[7]. P. Guerrier, G.Tosello, J. H.Hattel, Flow visualization and simulation of the filling process during injection molding, CIRP
Journal of Manufacturing Science and Technology, 16, 2017, 12-20.

[8]. F. D.Santis, R.Pantani, Development of a rapid surface temperature variation system and application to micro-injection molding, Journal of Materials Processing Technology, 237, 2016, 1-11.

[9]. S. C.Niana, C. Y.Wub, M. S. Huang, Warpage control of thin-walled injection molding using local mold temperatures, International Communications in Heat and Mass Transfer, 61, 2015, 102-110.

[10]. P.Estradaa, H. R. Sillera, E.Vázqueza, C. A. Rodrígueza, O.M. Romeroa, R. Corona, Micro-injection Moulding of Polymer Locking Ligation Systems, Procedia CIRP, 49, 2016, $1-7$. 